\title{
CoviD-19 Cross-skilling training to support medical redeployment in the COVID-19 pandemic
}

\author{
Authors: David Hettle, ${ }^{\mathrm{A}}$ Katherine Sutherland, ${ }^{\mathrm{B}}$ Edward Miles, ${ }^{\mathrm{C}}$ Lucy Allanby, ${ }^{\mathrm{A}}$ Zoe Bakewell, ${ }^{\mathrm{A}}$ Danielle Davies, ${ }^{\mathrm{A}}$ \\ Yasin Dhonye, ${ }^{\mathrm{A}}$ Victoria Handford, ${ }^{\mathrm{A}}$ Rebecca Upton, ${ }^{\mathrm{A}}$ Victoria Vilenchik ${ }^{\mathrm{A}}$ and Rebecca Wood ${ }^{\mathrm{A}}$
}

\begin{abstract}
During the response to the COVID-19 pandemic, doctors will be redeployed into roles with which they are unfamiliar. Adequate training must be provided to reacquaint doctors with medical ward practice, supporting psychological wellbeing and patient safety. Here we describe a cross-skilling programme in North Bristol NHS Trust designed to address colleague anxiety and support wellbeing during redeployment.
\end{abstract}

KEYWORDS: Medical education, redeployment, training, COVID-19, induction

DOI: $10.7861 /$ fhj.2020-0049

\section{Problem}

Planning for the sustainable delivery of patient care is a major challenge to all NHS trusts in the face of a potential COVID-19 surge. ${ }^{1,2}$ There is a need to redeploy doctors in training into roles with which they may be unfamiliar., ${ }^{1,3}$ Guidance from a host of organisations emphasises that adequate training and resources must be available to redeployed staff, appropriate to local requirements. ${ }^{4,5}$

North Bristol NHS Trust is a large secondary care acute trust and tertiary major trauma centre, employing 600 junior doctors and approximately 75 SAS grade doctors (staff grade, associate specialist and specialty doctors). Following a major service reorganisation in response to COVID-19, doctors were redeployed to support medical inpatient services at the main Southmead Hospital site. Throughout this process, we recognised the need to train and support redeployed staff to work in unfamiliar clinical environments, maintaining their psychological safety as well as their patients' physical wellbeing. In particular, trainees previously working in non-medical specialties required re-exposure to the day-to-day roles of a doctor practicing in medicine. This would further enable trust management to be assured of a crossskilled workforce ready for mobilisation as a contingency for the pandemic surge.

Authors: ${ }^{\mathrm{A} C l i n i c a l}$ teaching fellow, Southmead Hospital, Bristol, UK; ${ }^{B}$ anaesthetic registrar, Southmead Hospital, Bristol, UK and RCP chief registrar; 'Canaesthetic registrar and post-graduate education fellow, Southmead Hospital, Bristol, UK

\section{Potential solution}

We developed a cross-skilling learning programme in collaboration with medical consultants and trust management (Table 1), which included online and face-to-face elements. As far as possible, face-to-face components were undertaken in line with local social distancing measures, while still addressing critical training needed to prepare for redeployment. Our primary aim was to address colleague preparedness and support their wellbeing during redeployment. Doctors' involvement was strongly recommended for all non-medical trainees and any senior colleague who felt they would benefit from a 'refresher' on medical ward work.

\section{Table 1. COVID-19 medical training programme}

\begin{tabular}{|c|c|}
\hline COVID-19 summary & $\begin{array}{l}\text { Presentation } \\
\text { Video } \\
\text { eLearning package }\end{array}$ \\
\hline $\begin{array}{l}\text { Personal protective } \\
\text { equipment (PPE) }\end{array}$ & $\begin{array}{l}\text { PHE donning and doffing video links } \\
\text { Trust PPE update }\end{array}$ \\
\hline Medical scenarios & $\begin{array}{l}\text { Acute coronary syndrome with ECG } \\
\text { interpretation } \\
\text { Sepsis } \\
\text { Managing palliative and end-of-life } \\
\text { care }\end{array}$ \\
\hline Medical investigations & $\begin{array}{l}\text { Arterial blood gases (ABGs) } \\
\text { Chest X-rays } \\
\text { ECGs }\end{array}$ \\
\hline COVID-19 local guidance & $\begin{array}{l}\text { Assessment and treatment } \\
\text { escalation bundles } \\
\text { Palliative care guidance }\end{array}$ \\
\hline Resuscitation simulations & $\begin{array}{l}\text { Deteriorating patient } \\
\text { Advanced life support in COVID-19 } \\
\text { (in line with Resus Council [UK]) }\end{array}$ \\
\hline $\begin{array}{l}\text { Additional resources } \\
\text { document }\end{array}$ & $\begin{array}{l}\text { Relevant eLearning for Healthcare } \\
\text { (eLfH) packages } \\
\text { Local resources }\end{array}$ \\
\hline $\begin{array}{l}\text { COVID-19 wellbeing and } \\
\text { support guidance }\end{array}$ & \\
\hline
\end{tabular}


All participants completed a two-hour face-to-face session, supplemented by an online elearning module on the care of 'the non-intensive care unit respiratory patient'. The face-to-face element was delivered systematically by clinical teaching fellows, whose usual responsibility lies in preparing undergraduate medical trainees for their roles as junior doctors on the ward.

Following training, participants were distributed a summary of the face-to-face learning materials and a compendium of further online-based learning resources, useful in preparing for redeployment. All participants were asked to complete a postcourse evaluation considering the value of specific elements addressed in the course, such as the use of personal protective equipment (PPE) and the update on resuscitation, as well as its utility in supporting wellbeing and preparedness for redeployment.

\section{Results so far}

Of 288 doctors to receive training, 158 (55\%) completed the postcourse evaluation.

Our participants have comprised 75 (48\%) non-medical consultants, 10 (6\%) SAS doctors, $43(27 \%)$ specialty registrars, $24(15 \%)$ clinical fellow or core trainees and $6(4 \%)$ other grades. Over half of those attending had not worked on medical wards for over 10 years.

On a Likert-type scale (0-10), attendees were asked how prepared they felt for treating patients on medical wards. Prior to the course, mean and median responses were 3, improving to 5.7 (mean) and 6 (median) post-course, further illustrated in Fig 1.

Over half ( $53 \%$ ) of participants felt the course was pitched at the right level (median 5, IQR 0.5) to inform their necessary learning, with $97 \%(n=154)$ feeling the additional resources and links to further learning adequately enabled their preparedness. Free-text responses were used to identify areas in which staff felt they would have benefitted from additional face-to-face training: $75 \%(n=119)$ had no specific requests, $14 \%(n=23)$ requested additional training on specific conditions, $6 \%(n=9)$ on practical skills and $4 \%(n=7)$ on operational structures related to redeployment.

Further questioning focused on specific areas of training. Following the course, 150 participants (95\%) felt they understood the correct use of PPE during the pandemic, and 134 (85\%) were aware of the wellbeing support available to them.

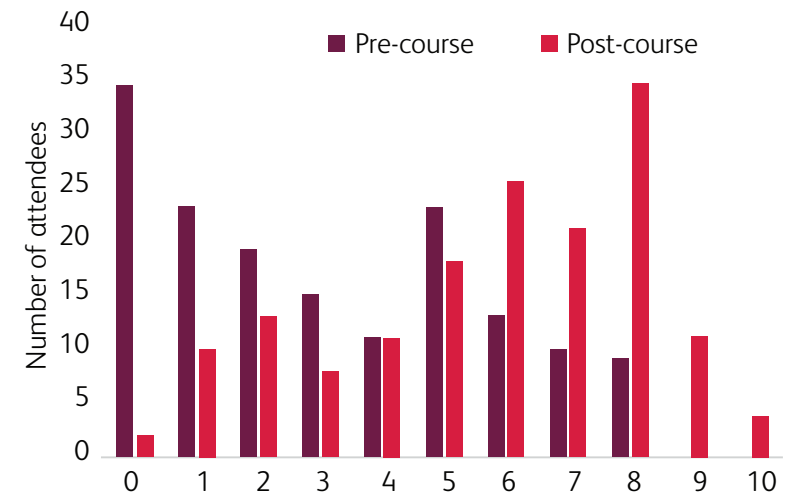

Preparedness ( $0=$ not prepared at all, $10=$ as prepared as possible)

Fig 1. Staff confidence in preparedness to treat patients on medical wards.

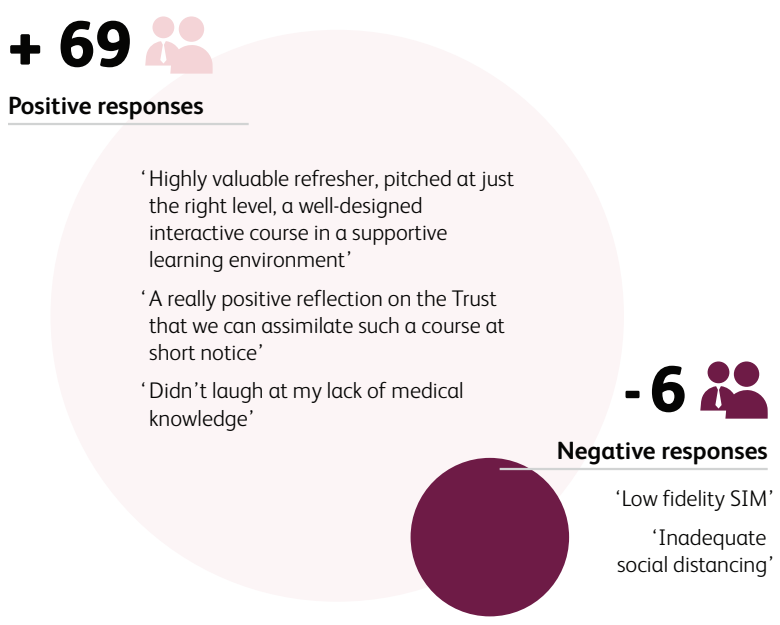

Fig 2. Illustration of free-text comments from attendees.

Generally the course was reflected on as positive ( $92 \%$ ), with Fig 2 illustrating free-text comments from attendees. Of the few negative reflections $(n=6)$, two attendees commented on a level too low for their learning needs, and a further two attendees reflected that there was inadequate social distancing despite best efforts to maintain this.

\section{Further evaluation}

This course demonstrates the hunger for appropriate training for those who are to be imminently redeployed into the medical workforce. In our organisation, nearly 300 doctors spanning most grades and non-physician specialties attended our cross-skilling programme in preparation for redeployment. Attendance was not mandated, only strongly encouraged.

Targeting doctors with less recent experience in the care of medical inpatients, our aim was to equip and ready staff for the benefit of individuals and the organisation. Staff confidence in managing medical inpatients improved dramatically, as shown in Fig 1. On an individual level, this represents Level 1 (reaction) and self-reported evidence of Level 2 (learning) on the Kirkpatrick model of evaluating training methods, ${ }^{6}$ illustrated in Fig 3. Further

\begin{tabular}{lll}
\hline & $\begin{array}{l}\text { Level 1 } \\
\text { Reaction }\end{array}$ & $\begin{array}{l}\text { Have participants enjoyed and found } \\
\text { training relevant? }\end{array}$ \\
\hline
\end{tabular}

Fig 3. Kirkpatrick model of evaluating training methods. ${ }^{6}$ 
evaluation assessing higher levels of evidence will become possible following redeployment. Nevertheless, the uptake of this course by nearly almost 300 doctors has developed high-level organisational assurance of appropriate training to its doctors, aligning to the requirements of individuals, our Trust and NHS England. ${ }^{5}$

Medical consultants, trust management, the RCP chief registrar and education fellows collaborated to develop the course content, ensuring all viewpoints on the requirements of training were considered. This enabled the inclusion of COVID-specific content alongside addressing trainee preparedness and wellbeing. As departmental inductions in our Trust vary in time and content, we replicated their use of face-to-face and online components but standardised the material delivered to provide a consistent basis for all redeployed staff. The delivery method - a 2-hour face-to-face session supplemented by online material-facilitated training best delivered in an interactive setting while minimising unnecessary social contact. The course content was widely recognised to be pitched at the right level. A minority of free-text answers reflected a desire for more focus on the management of specific medical conditions, though several of these respondents recognised the difficulties given time constraints. Further, a small number of participants remarked that despite efforts to maintain adequate social distancing, this was not successful. The challenge in balancing adequate distancing measures with delivering a reasonable-fidelity simulation, which accurately reflected real-life practice, led us to limit group numbers (to a maximum of four per simulation session), promote the allocation of roles which encouraged half of each group to be distant from the patient's bed, and debrief in socially distanced settings.

Delivering COVID-specific training, such as up-to-date PPE advice, and directing staff towards local and accessible wellbeing services was an important secondary aim of our programme. Given the challenges in measuring doctors' wellbeing ${ }^{7}$ we sought to align with the GMC's Caring for doctors, caring for patients, ${ }^{8}$ ensuring that attendees received clear guidance on wellbeing services, which have been locally expanded during the pandemic. The vast majority of responses reflect that our attendees were made aware of support; however, awareness does not always mean that doctors access wellbeing services. ${ }^{9}$ Therefore new team structures have incorporated a tool to address wellbeing at every team handover. Through future evaluation post-redeployment, we will be able to further assess the impacts of our training and the improved wellbeing services.

There are limitations to our programme, and adaptations should be considered when adopting our methods for use elsewhere. Firstly, we conducted the programme in a single educational setting, and some of the value of our course was gained by ensuring our participants' readiness for practice in our setting: for example, we used some of our time to ensure correct computer system access and training. The value of ensuring operational (alongside clinical) readiness should be addressed by those using this model elsewhere, including the involvement of local administrative and system-specific training support. Secondly, we recognise that confidence does not always correlate well to competence, ${ }^{10,11}$ though our model aimed to build participant confidence prior to redeployment such that competence could develop within redeployed team structures. It is necessary for such structures to build in safeguards and escalation policies to ensure patient safety remains paramount while operational competence develops.

\section{Potential future}

Following this success, we are continuing to provide training to other groups redeployed into the medical workforce, including retired doctors returning to practice. We are currently adapting the programme for use during interim Foundation Year 1 inductions. Our adaptations for this training are modelled on requirements outlined by the UK Foundation Programme Office. These include introducing documentation practice to simulation, task prioritisation scenarios, and prescribing practice in each relevant station.

Further evaluation of this training will be possible after several weeks' redeployment within new teams. However, learning within new team structures will not be limited to learning due to our training, and we are considering how to capture the frequent learning moments that will inevitably occur between members of traditionally different teams who now find themselves working alongside each other. By recording learning moments, the use of wellbeing services and a further follow-up survey we can continue to develop our service to promote learning and wellbeing.

\section{Conclusion}

Our programme provides an example of how we have addressed mandatory guidance from NHS England to provide medical redeployment training for doctors in the COVID-19 pandemic ${ }^{2-5}$ in a large NHS trust. We have evaluated the programme's impact on individuals' learning needs and its ability to equip our staff practically, educationally and psychologically to work outside the scope of their normal roles. Our programme's success, evidenced through responses from over 150 attendees, focused on principles of medical ward practice while outlining important COVID-specific learning and encouraging a spirit of adult learning through the distribution of further resources. Ongoing work will focus on how this adult learning mentality is maintained and stimulated further during the redeployment period. Our approach offers a novel framework which we will use and adapt for other groups and which could also be used in other NHS settings.

\section{Acknowledgements}

The authors would like to thank Dr Peter Creber, Dr Stephanie Eckoldt, Paul Grimes, Dr Ed Moran and Dr Claire Sellar for support in the development of course content, Dr Mohammed Bilal and Michael Harrison for supporting course delivery, Dr Katherine Finucane and Ms Catalina Estela for supervision and support, and Dr Jo Szram for facilitating rapid review of the manuscript in preparation for publication.

\section{References}

1 Willan J, King AJ, Jeffery K, Bienz N. Challenges for NHS hospitals during Covid-19 epidemic. BMJ 2020;368:m1117.

2 NHS England. Next steps on NHS response to COVID-19: Letter from Sir Simon Stevens and Amanda Pritchard. NHSE, 2020. Available from www.england.nhs.uk/coronavirus/uploads/ sites/52/2020/03/20200317-NHS-COVID-letter-FINAL.pdf [Accessed 8 April 2020].

3 Rimmer A. Covid-19: what do trainees need to know? BMJ 2020;368:m1276.

4 Olsson-Brown A. Letter: Plans regarding trainee redeployment during the COVID-19 pandemic: A position statement from the Academy Trainee Doctors' Group. Academy of Medical Royal 
Colleges, 2020. Available from www.aomrc.org.uk/wp-content/ uploads/2020/03/200326_ATGD_COVID-19-redeployment.pdf [Accessed 7 April 2020].

5 NHS England. Redeploying your secondary care medical workforce safely. NHSE, 2020. Available from www.england.nhs.uk/coronavirus/wp-content/uploads/sites/52/2020/03/Redeploying-yoursecondary-care-medical-workforce-safely_26-March.pdf [Accessed 8 April 2020]

6 Kirkpatrick DL, Kirkpatrick JD. Evaluating training programs, 3rd edn. San Francisco: Berrett-Koehler Publishers, 2006.

7 Lall MD, Gaeta T], Chung AS et al. Assessment of physician wellbeing, part one: Burnout and other negative states. West J Emerg Med 2019;20:278-90.

8 West M, Coia D. Caring for doctors, caring for patients. General Medical Council, 2019.
9 British Medical Association. Caring for the mental health of the medical workforce. BMA, 2019.

10 Barnsley L, Lyon PM, Ralston SJ et al. Clinical skills in junior medical officers: a comparison of self-reported confidence and observed competence. Med Educ 2004;38:358-67.

11 Brinkman DJ, Tichelaar ], van Agtmael MA, de Vries TP, Richir MC. Self-reported confidence in prescribing skills correlates poorly with assessed competence in fourth-year medical students. J Clin Pharmacol 2015;55:825-30.

Address for correspondence: Dr David Hettle, North Bristol Academy, North Bristol NHS Trust, Southmead Hospital, Bristol BS10 5NB, UK.

Email: d.hettle@nhs.net 